\title{
Required Treatment Expenditures for Hepatitis C Virus Infection and Advantage in the Reduction of Hepatocellular Carcinoma Incidence: Analysis of Possible Options in an Endemic Area
}

\begin{abstract}
Background: Hepatitis $\mathrm{C}$ virus (HCV) infection is a known underlying factor contributing to hepatocellular carcinogenesis. The use of direct-acting antiviral (DAA) medication is a form of clinical management for controlling HCV infection and reducing the hepatocellular carcinoma incidence. This medication is introduced to several endemic areas. The big concern is on the treatment expenditures. Several alternative options are proposed and it is required to assess the effect of each alternative option. Objective: Here, the authors assessed and estimated the required treatment expenditures for HCV infection and advantage in the reduction of hepatocellular carcinoma incidence based on the analysis of possible options in an endemic area. Methods: A medical economics analysis was done. Results: According to the cost-utility analysis, the best alternative option that is hereby recommended is DAA medication coverage for all cases. Conclusion: DAA medication coverage for all cases is recommended.
\end{abstract}

Keywords: Expenditure, hepatitis $C$, incidence, infection, treatment

\section{Introduction}

Hepatitis $\mathrm{C}$ infection is a known underlying factor contributing to hepatocellular carcinogenesis. The use of direct-acting antiviral (DAA) medication is a form of clinical management for controlling hepatitis $\mathrm{C}$ virus (HCV) infection and reducing the hepatocellular carcinoma incidence. ${ }^{[1]}$ This medication is introduced to several endemic areas with a hope that it can help better control and eradicate diseases. ${ }^{[2]}$ Roche et al. concluded that it is essential to study the effectiveness of DAA medication for the conclusion of the advantage. ${ }^{[3]}$

In Thailand, HCV infection is also very common. The use of DAA medication is the new public health strategy to counteract $\mathrm{HCV}$ infection and its complications. ${ }^{[4-6]}$ Poovorawan et al. proposed a dramatical decrease of $\mathrm{HCV}$ infection and its complications including hepatocellular carcinoma within a 20-year period of implementation of DAA medication. ${ }^{[5]}$ The huge concern is on the treatment expenditures. Several alternative options are proposed and it is required to

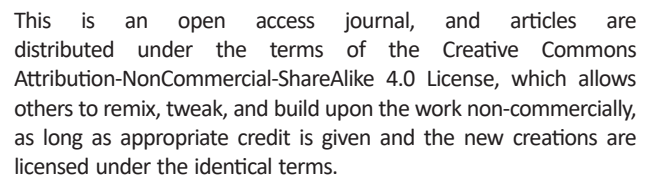

For reprints contact: reprints@medknow.com assess the effect of each alternative option. Here, the authors assess and estimate the required treatment expenditures for $\mathrm{HCV}$ infection and advantages in the reduction of hepatocellular carcinoma incidence based on an analysis of possible options in an endemic area.

\section{Materials and Methods}

The main aim of this study is to estimate the required treatment expenditures for $\mathrm{HCV}$ infection and advantages in the reduction of hepatocellular carcinoma incidence based on an analysis of possible options in an endemic area, Thailand. The basic data on expenditure required for DAA medication in the setting are referred to a previous nationwide study. ${ }^{[4]}$ The estimation of required expenditures is done according to the path probability of each possible option to expand the coverage of DAAs as follows: (a) coverage for all cases, (b) expanded selective coverage for cases with fibrosis in the range of F2-F4 which is the present strategy in the study setting, (c) doubling the number of DAA treatments plus coverage for all cases, and (d) doubling the number of DAA treatments plus selective coverage expanded selective

How to cite this article: Joob B, Wiwanitkit V.
Required treatment expenditures for Hepatitis C
virus infection and advantage in the reduction of
hepatocellular carcinoma incidence: Analysis of
possible options in an endemic area. Indian J Med
Paediatr Oncol 2019;40:481-3.

How to cite this article: Joob B, Wiwanitkit V. Required treatment expenditures for Hepatitis $C$ virus infection and advantage in the reduction of possible options in an endemic area. Indian $\mathrm{J}$ Med Paediatr Oncol 2019;40:481-3.

\section{Beuy Joob1, Viroj Wiwanitkit ${ }^{2,3,4}$}

${ }^{1}$ Sanitation 1 Medical Academic Center, Bangkok, Thailand, ${ }^{2}$ Department of Community Medicine, Dr. DY Patil University, Pune, Maharashtra, India, ${ }^{3}$ Department of Tropicla Medicine, Hainan Medical University, Haikou, China,

${ }^{4}$ Department of Medical Science, Faculty of Medicine, University of Nis, Niš, Serbia

Submitted: 02-May-2018 Accepted in Revised Form: 21-Jun-2018

Published: 17-Feb-2020

Address for correspondence: Dr. Beuy Joob,

Sanitation 1 Medical Academic Center, Bangkok, Thailand.

E-mail: beuyjoob@hotmail.com

Access this article online

Website: www.ijmpo.org

DOI: 10.4103/ijmpo.ijmpo_101_18 Quick Response Code:

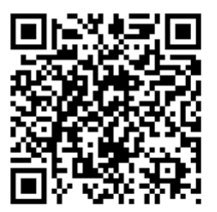




\begin{tabular}{lccc}
\hline $\begin{array}{r}\text { Table 1: The expected required expenditure and } \\
\text { advantage in each alternative option for direct-acting } \\
\text { antiviral medications }\end{array}$ \\
\hline $\begin{array}{l}\text { Alternative } \\
\text { option }^{\mathbf{a}}\end{array}$ & $\begin{array}{c}\text { Expected expenditure } \\
\text { (million USD) }\end{array}$ & $\begin{array}{c}\text { Coverage } \\
(\mathbf{\%})^{\mathbf{b}}\end{array}$ & $\begin{array}{c}\text { Expected } \\
\text { advantage (\%) }\end{array}$ \\
\hline 1 & 1494 & 100 & 82.5 \\
2 & 1240 & 83 & 37.7 \\
3 & 2988 & 100 & 100 \\
4 & 2480 & 83 & 64.1 \\
\hline
\end{tabular}

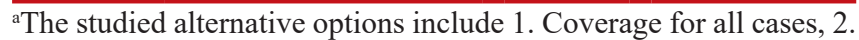
Expanded selective coverage for cases with fibrosis in the range of F2-F4, 3. Doubling the number of DAA treatments plus coverage for all cases, and 4. Doubling the number of DAA treatments plus selective coverage expanded selective coverage for cases with fibrosis in the range of $\mathrm{F} 2-\mathrm{F} 4,{ }^{\mathrm{b}} \mathrm{Coverage}$ is hereby referred to the percentage of the patients with hepatitis $C$ that will be covered by each alternative option and referred to the previous report by Poovorawan et al., ${ }^{[5]}$ ${ }^{\mathrm{c}}$ Expanded coverage is defined as the expected reduction rate of hepatitis C-related hepatocellular carcinoma incidence referred to the previous reports by Wasitthankasem et al. ${ }^{[4]}$ and Duberg et al. ${ }^{[6]}$ DAAs - Direct-acting antivirals

\begin{tabular}{|c|c|c|c|}
\hline $\begin{array}{l}\text { Alternative } \\
\text { optiona }^{\text {a }}\end{array}$ & $\begin{array}{c}\text { Cost } \\
\text { (USD) }^{\mathrm{b}}\end{array}$ & $\begin{array}{c}\text { Expected } \\
\text { advantage }(\%)^{\mathrm{c}}\end{array}$ & $\begin{array}{l}\text { Cost utility } \\
\text { (USD) }^{\mathrm{d}}\end{array}$ \\
\hline 1 & 1494 & 82.5 & 1810.91 \\
\hline 2 & 1240 & 37.7 & 3289.1 \\
\hline 3 & 2988 & 100 & 2988 \\
\hline 4 & 2480 & 64.1 & 3868.96 \\
\hline
\end{tabular}

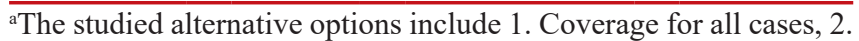
Expanded selective coverage for cases with fibrosis in the range of F2-F4, 3. Doubling the number of DAA treatments plus coverage for all cases, and 4. Doubling the number of DAA treatments plus selective coverage expanded selective coverage for cases with fibrosis in the range of $\mathrm{F} 2-\mathrm{F} 4$, ${ }^{\mathrm{b}} \mathrm{Cost}$ is defined as expected expenditure as shown in Table 1, 'Ctility is defined as expected advantage as shown in Table 1 , ${ }^{\mathrm{d}}$ Cost utility is calculated by cost divided by utility. DAAs - Direct-acting antivirals

coverage for cases with fibrosis in the range of F2-F4. The advantage in each alternative option is also estimated and is defined as the expected reduction rate of HCV-related hepatocellular carcinoma incidence with reference to the previous reports by Wasitthankasem et al. ${ }^{[4]}$ for general local population and Duberg et al. ${ }^{[5]}$ for increasing the effectiveness of doubling DAA medication. Cost-utility analysis is further performed comparing each alternative option.

\section{Results}

According to this study, the expected required expenditure and advantage in each alternative option for DAA medication is shown in Table 1. According to the results obtained from the cost-utility analysis [Table 2], the best alternative option recommended is the DAA medication coverage for all cases.

\section{Discussion}

The use of DAA medication is the hope for successful management of $\mathrm{HCV}$ infection and HCV-related disease including hepatocellular carcinoma. The eradication of the disease is usually mentioned. Nevertheless, the huge obstacle for achieving the target is the expenditure for medication. In Thailand, HCV infection is not uncommon and is an important contributing cause of hepatocellular carcinoma. The introduction of DAA medication becomes the new public health strategy in the control of HCV infection and hepatocellular carcinoma in Thailand. ${ }^{[4]}$ Due to the high expenditure, the proposal for reducing the cost of DAAs is raised and expected to be the way to reach the success in HCV elimination. ${ }^{[4]}$

Based on the present study, it can be confirmed that there is a possibility that $\mathrm{HCV}$ eradication and control of HCV-related hepatocellular carcinoma are possible in Thailand. The use of coverage for all cases plus doubling DAA medication is the alternative option that can help achieve that target. Nevertheless, the expenditure is still the huge consideration. Chhatwal et al. noted that there was a requirement for analysis of the real situation in the developing countries in endemic areas, which could reflect the real advantage of implementation of DAA medication. ${ }^{[7]}$ According to the present cost-utility analysis, the presently used strategies, expanded selective coverage for cases with fibrosis in the range of $\mathrm{F} 2-\mathrm{F} 4$, is not the most appropriate alternative. The best alternative option that is hereby recommended is DAA medication coverage for all cases.

\section{Conclusion}

In this work, a medical economic analysis was done to find the most appropriate option for HCV treatment with aim at reduction of hepatocellular carcinoma. According to the present medical economics analysis, the DAA medication coverage for all cases is the most preferable option.

\section{Financial support and sponsorship}

Nil.

\section{Conflicts of interest}

There are no conflicts of interest.

\section{References}

1. Puchades Renau L, Berenguer M. Introduction to hepatitis $\mathrm{C}$ virus infection: Overview and history of hepatitis $\mathrm{C}$ virus therapies. Hemodial Int 2018;22 Suppl 1:S8-21.

2. Braillon A. Direct-acting antiviral drugs and hepatitis $\mathrm{C}$ virus: A therapeutic revolution? Cancer 2015;121:4268-9.

3. Roche B, Coilly A, Duclos-Vallee JC, Samuel D. The impact of treatment of hepatitis $\mathrm{C}$ with DAAs on the occurrence of HCC. Liver Int 2018;38 Suppl 1:139-45.

4. Wasitthankasem R, Vichaiwattana P, Siripon N, Posuwan N, Auphimai C, Klinfueng $\mathrm{S}$, et al. Liver disease burden and required treatment expenditures for hepatitis $\mathrm{C}$ virus $(\mathrm{HCV})$ 
infection in Thailand: Implications for $\mathrm{HCV}$ elimination in the new therapeutic era, a population-based study. PLoS One 2018;13:e0196301.

5. Poovorawan K, Pan-Ngum W, White LJ, Soonthornworasiri N, Wilairatana P, Wasitthankasem R, et al. Estimating the impact of expanding treatment coverage and allocation strategies for chronic hepatitis $\mathrm{C}$ in a direct antiviral agent era. PLoS One 2016;11:e0163095.
6. Duberg AS, Blach S, Falconer $\mathrm{K}$, Kåberg $\mathrm{M}$, Razavi $\mathrm{H}$, Aleman $\mathrm{S}$, et al. The future disease burden of hepatitis $\mathrm{C}$ virus infection in Sweden and the impact of different treatment strategies. Scand J Gastroenterol 2015;50:233-44.

7. Chhatwal J, He T, Lopez-Olivo MA. Systematic review of modelling approaches for the cost effectiveness of hepatitis $\mathrm{C}$ treatment with direct-acting antivirals. Pharmacoeconomics 2016;34:551-67. 